\title{
Monitoring Durability of Limestone Cement Paste Stored at Conditions Promoting Thaumasite Formation
}

\author{
Konstantinos Sotiriadis ${ }^{1}$, Michal Hlobil ${ }^{1}$, Jaromír Toušek ${ }^{2}$, Dita Machová ${ }^{1}$, Petra \\ Mácová $^{1}$, Michal Vopálenský ${ }^{1}$ and Alberto Viani ${ }^{1}$ \\ ${ }^{1}$ Institute of Theoretical and Applied Mechanics of the Czech Academy of Sciences, Prosecká 809/76, \\ 19000 Prague 9, Czechia, sotiriadis@itam.cas.cz \\ ${ }^{2}$ CEITEC - Central European Institute of Technology, Masaryk University, Kamenice 5/A4, 62500 \\ Brno, Czechia, tousek@chemi.muni.cz
}

\begin{abstract}
The durability of Portland-limestone cement with high limestone content was monitored at conditions promoting thaumasite formation. Pore structure and deterioration characteristics were assessed with X-ray micro-computed tomography and correlated with material's strength. Changes in crystalline and amorphous phases of the cement paste were investigated with X-ray powder diffraction and solid state nuclear magnetic resonance spectroscopy. Rapid deterioration was observed, evolving as a front causing concentric crack patterns followed by detachment of the part of specimen in contact with the corrosive solution. This ultimately led to loss of structural integrity after 4 months of exposure. During sulfate attack, thaumasite, ettringite and gypsum formed at the expense of portlandite, calcite and monocarboaluminate hydrate. Furthermore, polymerization of silicate chains in $\mathrm{C}-\mathrm{S}-\mathrm{H}$ and deterioration of $\mathrm{C}-\mathrm{S}-\mathrm{H}$ also occurred.
\end{abstract}

Keywords: Limestone Cement, Thaumasite Sulfate Attack, Microstructure, Solid State NMR Spectroscopy, X-Ray Micro-Computed Tomography.

\section{Introduction}

Portland-limestone cements (EN 197-1:2011), developed as alternative to ordinary Portland cement, are characterized by competitive properties and lower environmental impact (Tsivilis et al., 2000; Worrell et al., 2013). These features are in line with the global trend towards the reduction of $\mathrm{CO}_{2}$ emissions and energy needs of the cement production process, and with the rationalization of raw materials usage as well. However, the high limestone content increases the risk for a specific type of sulfate attack, occurring at low temperature and excess humidity. Under such conditions, sulfate and carbonate ions react with calcium silicate hydrates $(\mathrm{C}-\mathrm{S}-\mathrm{H})$, leading to the formation of thaumasite $\left(\mathrm{CaSiO}_{3} \cdot \mathrm{CaCO}_{3} \cdot \mathrm{CaSO}_{4} \cdot 15 \mathrm{H}_{2} \mathrm{O}\right)$ and, subsequently, to the deterioration of the hardened material (Irassar, 2009).

Long-term mechanical performance of limestone cement concrete exposed to conditions promoting this type of chemical attack is, thus, a crucial issue in real structures. A model able to predict the mechanical properties of cementitious materials in sulfate-bearing environments would allow for optimizing concrete composition both in terms of durability and environmental impact. Aiming at the development of a predictive mathematical model, this study is focused on obtaining necessary data concerning the microstructure and strength of the material.

Insights into the pore structure of Portland-limestone cement paste specimens were obtained with X-ray micro-computed tomography (XmCT), following an approach similar to previous studies (Yang et al., 2018; Ma et al., 2018). Paste compressive strength was correlated with the 
damage observed in the specimens. Changes in phase composition were monitored with X-ray powder diffraction (XRPD) with the Rietveld method and solid state nuclear magnetic resonance spectroscopy (ssNMR); the usage of these techniques allowed for assessing both crystalline and amorphous fraction of the hardened cement paste (Álvarez-Pinazo et al., 2012; Richardson et al., 2010).

\section{Experimental}

\subsection{Materials}

Portland-limestone cement paste was produced (water-to-cement ratio of 0.45) employing a commercial CEM II/B-LL cement (Cement Hranice, a.s.), and casted in the form of cylinders $(\mathrm{d}=20 \mathrm{~mm} ; \mathrm{h}=50 \mathrm{~mm})$. The paste remained in the molds for $24 \mathrm{~h}$. After demolding, the specimens were water-cured for 27 days, and then exposed to magnesium sulfate solution (S) of $20 \mathrm{~g} / \mathrm{L} \mathrm{SO}_{4}{ }^{2-}$ content until loss of structural integrity, and in water (W) as reference, both at

\subsection{Tests}

Tests were performed after initial curing (at 28 days) and then regularly on specimens stored in magnesium sulfate solution and water.

Cylinders were scanned with the custom developed patented Twinned Orthogonal
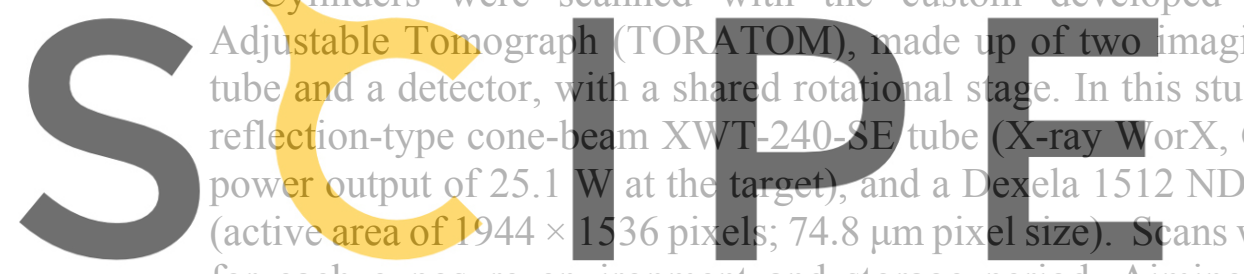

for each exposure environment and storage period. Aiming at sufficient magnification for

Register for free at https/\%www. scipedia. com to the source-tosample distance and sample-todetector distance were properly adjusted. A total number 013208 projections were collected lor

each tomographic scan, which were flat-field corrected. VG Studio Max software was employed to obtain 3D models, using filtered back projection algorithm. Visualization of the data acquired was accomplished with ImageJ software. Quantitative image analysis of the cement matrix was carried out on volumes of interest, cut from the original volume and excluding large defects (pores, cracks), using Pore3D software which allowed for deriving porosity, specific surface area of pores $\left(S_{v}\right)$, and integral of mean curvature of pores $\left(M_{v}\right)$.

Compressive strength tests were performed on five specimens for each exposure environment and storage period. The results are the average values from five measurements.

Fractions from cylinders stored in water, and material obtained from the deteriorated surface of the specimens exposed to magnesium sulfate solution, were powdered (particle size below $63 \mu \mathrm{m}$ ) and employed for XRPD and ssNMR spectroscopy measurements. One specimen stored in water and eight specimens stored in sulfate solution, were used for each storage period.

XRPD data were collected with a Bruker D8 Advance diffractometer [CuKa radiation $(\lambda=$ $1.5418 \AA)]$ in the angular range $5-80^{\circ} 2 \theta$, at $40 \mathrm{kV}$ and $40 \mathrm{~mA}$. Rietveld refinements of the XRPD patterns were performed with the TOPAS 4.2 software (Bruker AXS), allowing for quantitative phase analysis (QPA). The internal standard method was applied for determining 
the amorphous fraction.

One-pulse ${ }^{29} \mathrm{Si}$ MAS NMR spectra were collected at $25^{\circ} \mathrm{C}$ with a Bruker Avance-Neo 500 spectrometer (magnetic field of $11.75 \mathrm{~T}$ ), using a 4-mm CP/MAS probe at the Larmor frequency of 99.4 MHz. Samples were loaded into a zirconium oxide rotor (4 $\mathrm{mm}$ in diameter) spinning at $12.5 \mathrm{kHz}$. As external reference, 4,4-dimethyl-4-silapentane-1-sulfonic acid (DSS) (0.0 ppm) was used. 10000 scans were recorded during each measurement with $4.0 \mu$ s pulse length, and 20 s relaxation delay. Components of ${ }^{29}$ Si MAS NMR spectra were deconvoluted with PeakFit 4.12 software (Systat Software).

\section{Results and Discussion}

Sulfate attack resulted in rapid disintegration of the specimens; structural integrity was lost already after 3.5-4 months, not allowing for performing further compressive strength tests. XRPD and ssNMR measurements on samples obtained from the deteriorated part of the specimens continued up to 5 months.

In Figure 1, cross sectional XmCT slices of specimens exposed for 3 (left) and 4 (right) months to magnesium sulfate solution, are illustrated. The deterioration proceeded through the formation of concentric cracks, as indicated by the white arrows, resulting in expansion of the specimen and, eventually, detachment of the damaged part. As the process evolved, concentric cracks formed closer to the center of the cylinder, pointing to a layer-type deterioration.


Register for free at https//www.scipedia.com to download the version without the watermark

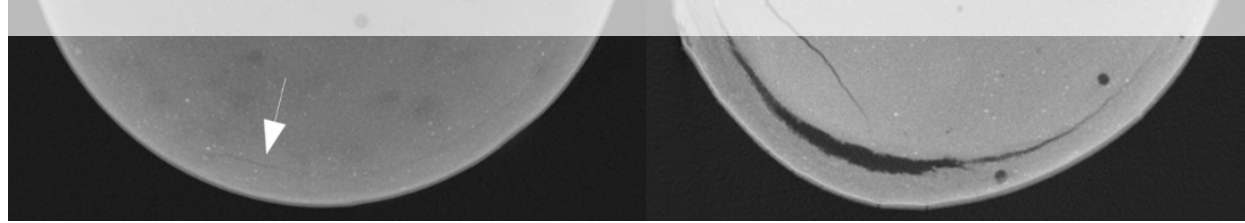

Figure 1. Cross sectional XmCT images of specimens exposed to magnesium sulfate solution for 3 months (left) and 4 months (right); white arrows indicate cracks formed due to sulfate attack.

Quantitative image analysis of the reconstructed volumes allowed for obtaining detailed information about the microstructure of the specimens. The values determined for porosity, $S_{v}$ and $M_{v}$ are summarized in Table 1 . They indicate that the microstructure of the sound part of specimens exposed to S solution resembles to that of the specimens stored in W, supporting the assumption that sulfate attack proceeded as a deterioration front moving from the surface to the center of the specimen. Although attention was paid for excluding large defects during analysis, slightly higher average values were calculated for the specimens stored in S solution. Considering that entrapped air should be on average the same in all samples, random 
Konstantinos Sotiriadis, Michal Hlobil, Jaromír Toušek, Dita Machová, Petra Mácová, Michal Vopálenský and Alberto Viani

irregularities in the matrix of the deteriorated specimens were most likely included in the reconstructed volumes processed, affecting the results.

Table 1. Numerical results derived from quantitative analysis of XmCT images relative to the sound part of the specimens $\left(S_{v}\right.$ : specific surface area of pores; $M_{v}$ : integral of mean curvative of pores).

\begin{tabular}{ccccccc}
\hline & \multicolumn{3}{c}{ Specimens exposed to W } & \multicolumn{3}{c}{ Specimens exposed to S } \\
\hline $\begin{array}{c}\text { Exposure period } \\
(\text { months })\end{array}$ & $\begin{array}{c}\text { Porosity } \\
(\%)\end{array}$ & $\begin{array}{c}S_{v} \\
\left(\mathrm{~mm}^{-1}\right)\end{array}$ & $\begin{array}{c}M_{v} \\
\left(\mathrm{~mm}^{-2}\right)\end{array}$ & $\begin{array}{c}\text { Porosity } \\
(\%)\end{array}$ & $\begin{array}{c}S_{v} \\
\left(\mathrm{~mm}^{-1}\right)\end{array}$ & $\begin{array}{c}M_{v} \\
\left(\mathrm{~mm}^{-2}\right)\end{array}$ \\
\hline REF & 0.26 & 0.34 & 36.28 & - & - & - \\
\hline 1 & 0.34 & 0.85 & 529.71 & 0.78 & 1.50 & 215.11 \\
\hline 2 & 0.39 & 0.86 & 536.45 & 0.70 & 1.48 & 457.38 \\
\hline 3 & 0.65 & 0.95 & 66.25 & 0.64 & 2.82 & 606.24 \\
\hline 4 & 1.02 & 1.55 & 193.24 & 0.49 & 1.20 & 214.76 \\
\hline Average & 0.53 & 0.91 & 272.39 & 0.65 & 1.75 & 373.37 \\
\hline
\end{tabular}

In Figure 2, the compressive strength of the specimens exposed to sulfate solution relative to that measured for the specimens stored in water, is presented. Although the damage is not extensive at 3 months (Figure 1), the specimens had lost already 55\% of their strength by this time, pointing to a rapid decline of compressive strength due to deterioration.

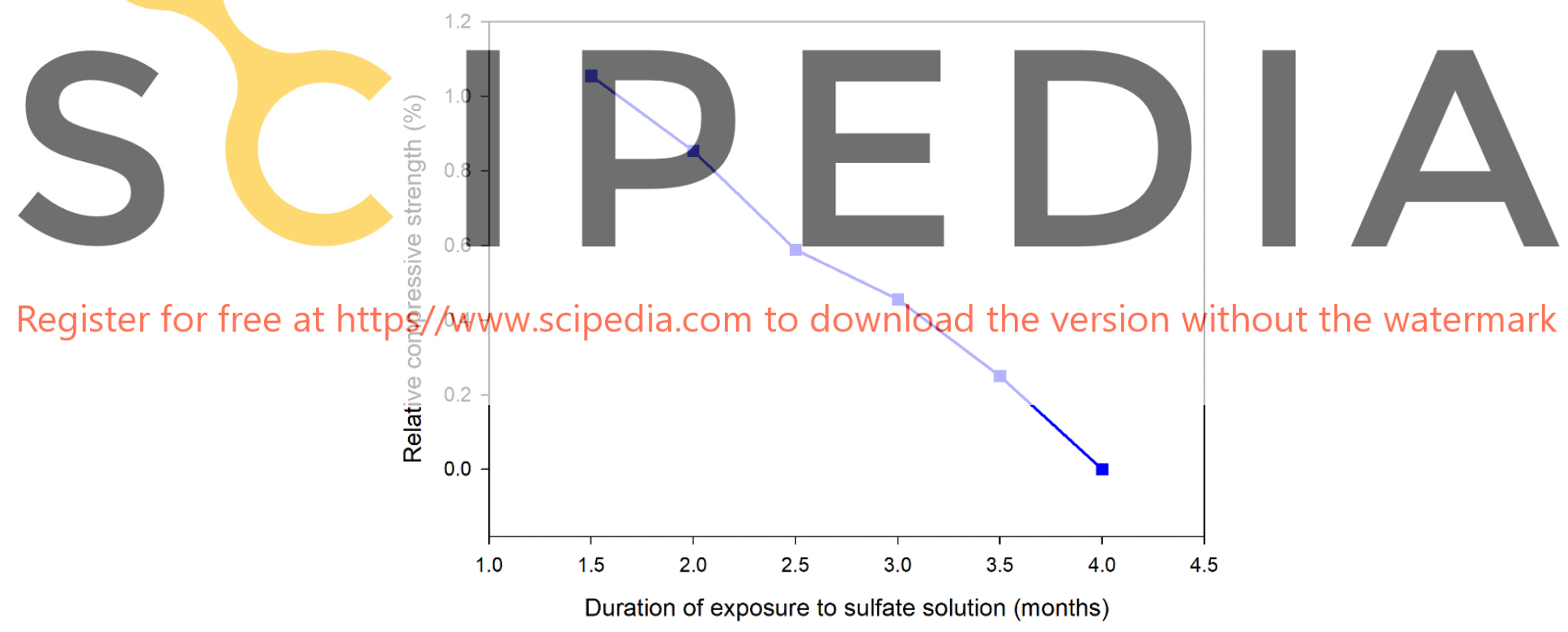

Figure 2. Relative compressive strength of specimens exposed to sulfate solution and water.

QPA results are summarized in Table 2. Decreasing amounts of belite were detected in the specimens stored in water, contrary to the other clinker phases which are absent already at 3 months. Large quantities of portlandite and traces of hydrogarnet were detected in these specimens. Gypsum was consumed towards ettringite formation. Reduction in calcite content and formation of carboaluminate hydrates indicated the participation of calcite in the hydration process of cement. During sulfate attack, ettringite content increased, whilst gypsum and thaumasite formed. The formation of these minerals is directly linked to the consumption of 
portlandite and carboaluminates, and to the decrease in calcite content. Sulfate attack led to significant reduction of the amorphous fraction, pointing to severe degradation of calcium silicate hydrate phase, which is the main amorphous component of the hardened cement paste. The presence of brucite was inherited from the magnesium content of the corrosive solution.

Table 2. Quantitative phase analysis (wt.\%) of the cement used, of the samples obtained from specimens exposed to $\mathrm{W}$, and from the deterioated part of spesimens exposed to $\mathrm{S}$.

\begin{tabular}{|c|c|c|c|c|c|c|c|}
\hline \multirow[t]{2}{*}{ Phase } & \multirow[t]{2}{*}{ Cement } & \multicolumn{3}{|c|}{ Exposure period to W (months) } & \multicolumn{3}{|c|}{ Exposure period to $\mathrm{S}$ (months) } \\
\hline & & 3 & 4 & 5 & 3 & 4 & 5 \\
\hline Alite & 32.5 & - & - & - & - & - & - \\
\hline Belite & 6.0 & 1.0 & 1.4 & 0.7 & - & - & - \\
\hline $\mathrm{C}_{3} \mathrm{~A}$ & 2.5 & - & - & - & - & - & - \\
\hline Brownmillerite & 3.9 & 一 & 一 & - & - & - & - \\
\hline Hydrogarnet & - & $<1.0$ & $<1.0$ & $<1.0$ & - & - & - \\
\hline Monocarboaluminate & - & 3.6 & 3.4 & 3.4 & - & - & - \\
\hline Hemicarboaluminate & - & $<0.5$ & $<0.5$ & $<0.5$ & - & - & - \\
\hline Portlandite & - & 12.6 & 11.6 & 10.4 & $<0.5$ & $<0.5$ & $<0.5$ \\
\hline Gypsum & 3.2 & - & - & - & 26.8 & 38.3 & 39.3 \\
\hline Ettringite & - & 6.1 & 5.5 & 5.8 & 7.6 & 7.2 & 9.2 \\
\hline Thaumasite & - & - & - & - & 4.5 & 1.1 & 2.3 \\
\hline Calcite & 22.7 & 13.4 & 16.0 & 16.8 & 7.1 & 8.8 & 9.5 \\
\hline Brucite & - & & - & - & 3.5 & 2.8 & \\
\hline Amorphous & 29.0 & 62.0 & 61.0 & 62.0 & 50.2 & 42.0 & \\
\hline
\end{tabular}

Register for freelat https//www.scipedia.com todownload the version without the watermark
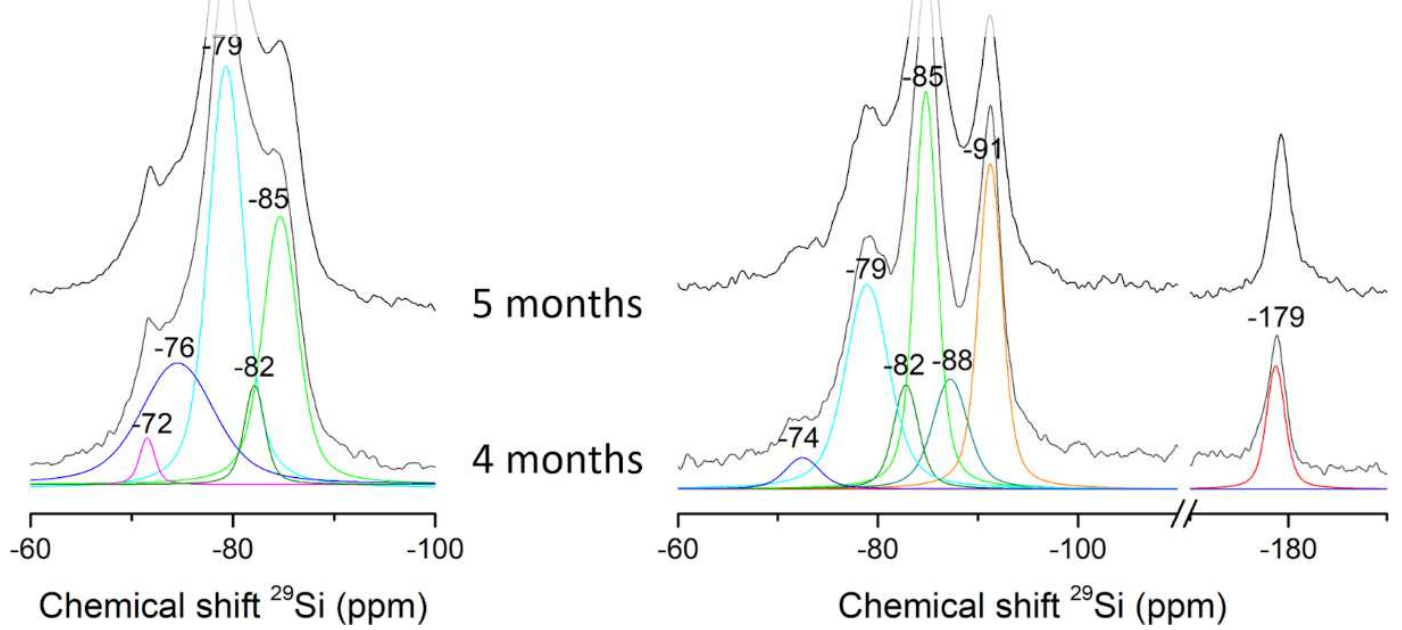

Figure 3. ${ }^{29} \mathrm{Si}$ MAS NMR spectra collected at 4 and 5 months for specimens stored in water (a) and for samples obtained from the deteriorated surface of specimens exposed to magnesium sulfate solution (b). Black curves: experimental spectra; Colored curves: deconvoluted spectra. 
Five components were detected in the water-cured specimens with isotropic chemical shifts at around $-85 \mathrm{ppm},-82 \mathrm{ppm},-79 \mathrm{ppm},-76 \mathrm{ppm}$ and $-72 \mathrm{ppm}$. The first three values correspond to $Q^{2}, Q^{2}(1 \mathrm{Al})$ and $Q^{1}$ species, respectively, which are characteristic for the $\mathrm{C}-\mathrm{S}-\mathrm{H}$ phase (Walkley and Provis, 2019; Richardson et al., 1993; Kunther et al., 2015). The quite broad component at $-76 \mathrm{ppm}$ is in close proximity to the isotropic chemical shift values assigned to anhydrated alite grains (Rawal et al., 2010), indicating an amorphous environment which is related to hydrated clinker grains. The isotropic chemical shift at $-72 \mathrm{ppm}$ is characteristic of unreacted belite (Andersen et al., 2003), in agreement with XRPD results.

$Q^{2}, Q^{2}(1 \mathrm{Al})$ and $Q^{1}$ species were also identified in the samples obtained from the deteriorated surface of specimens exposed to $\mathrm{S}$ solution. Another component at around $-88 \mathrm{ppm}$, attributed to bridging $\mathrm{SiO}_{4}$ tetrahedra in $\mathrm{C}-\mathrm{S}-\mathrm{H}$ connected to each other through hydrogen bonding $\left(Q^{2} \mathrm{u}\right.$ species) (L' Hôpital et al., 2015), was identified in these samples. In addition, two more components were detected; one at -179 ppm assigned to $\mathrm{SiO}_{6}$ group, which is characteristic of the thaumasite structure (Grimmer et al., 1986), and another at -91 ppm which is attributed to $Q^{3}(1 \mathrm{Al})$ species in cross-linked aluminosilicate chains (Richardson et al., 2010). The presence of both components points to deterioration of $\mathrm{C}-\mathrm{S}-\mathrm{H}$ phase during sulfate attack. The broad shape of the component at around $-73 \mathrm{ppm}$, most likely, corresponds to partially hydrated clinker phases, since there is no indication of anhydrated grains in the XRPD patterns. Quantitative results derived from the deconvolution of spectra are reported in Table 3.

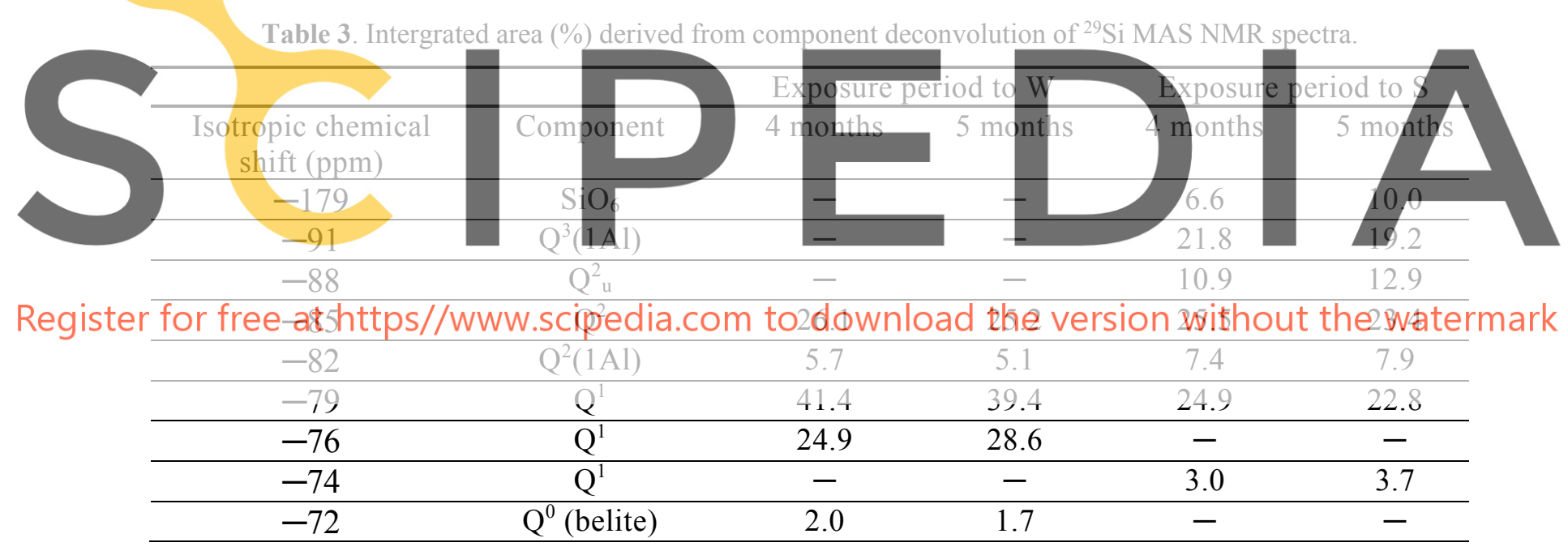

Minor differences were observed between samples obtained from specimens exposed for 4 and 5 months to the same environment. The main observation, regarding the water-cured specimens, is the increase of the component at $-76 \mathrm{ppm}$ and the decrease of the one at -72 , indicating the ongoing hydration of clinker. In samples obtained from deteriorated specimens, the increase in the content of $\mathrm{SiO}_{6}$ component with time is related to the increase of thaumasite content, as confirmed by XRPD (Table 2). Comparison of the sulfate-affected specimens with those stored in water reveals that, besides thaumasite formation, sulfate attack led to consumption of $Q^{0}$ phases and polymerization of silicate chains (formation $Q^{2}, Q^{2}$ and $Q^{3}(1 \mathrm{Al}$ ) species at the expense of $Q^{1}$ ). 


\section{Conclusions}

- The aggressive chemical environment employed in the study produced intense deterioration of the limestone cement paste specimens, which resulted in the rapid decline of compressive strength.

- Deterioration proceeded as a front that initiated through the formation of concentric crack patterns, followed by detachment of the sulfate-affected external part from the sound core.

- Thaumasite, ettringite and gypsum formed during sulfate attack at the expense of portlandite, calcite, monocarboaluminate hydrate and $\mathrm{C}-\mathrm{S}-\mathrm{H}$; gypsum was the most abundant deterioration product, whose quantity increased with time.

- Sulfate attack promoted polymerization of silicate chains in C-S-H (increase of $Q^{2}$ and increase of $Q^{1}$ species), and extensive deterioration of $\mathrm{C}-\mathrm{S}-\mathrm{H}$ phase as indicated from the presence of $Q^{3}(1 \mathrm{Al})$ component.

The collected quantitative data will be employed in the development of a micromechanical model for predicting mechanical properties of cementitious materials exposed to thaumasite sulfate attack.

\section{Acknowledgements}

The study was performed within the project "Experimental quantification and modelling of deterioration in Portland-limestone cement pastes affected by thaumasite sulfate attack" (grant number 18-26056Y), supported by the Czech Science Foundation (GAČR). CIISB research infrastructure project Livi2015043 funded Education, Youth and Sport measurements at the CF Josef

ORCID

Konstantinos Sotiriadis: hetp
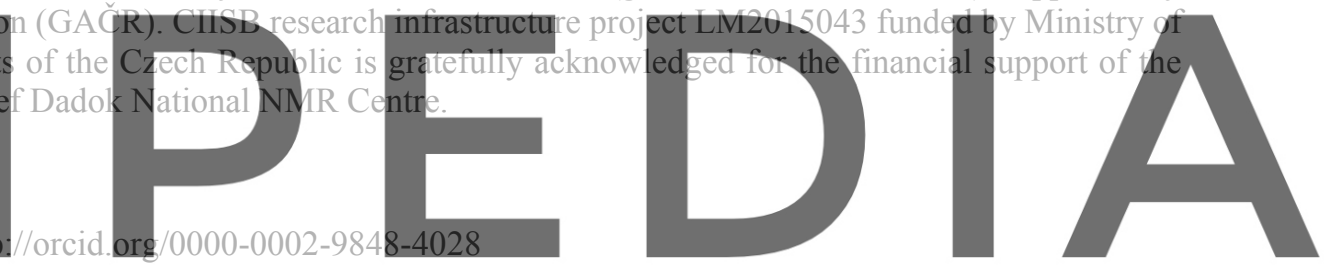

Michal Hlobil: http://orcid.org/0000-0001-5818-7320



Petra Mácová: http://orcid.org/0000-0002-8277-133X

Michal Vopálenský: http://orcid.org/0000-0002-9932-6486

Alberto Viani: http://orcid.org/0000-0002-6019-1094

\section{References}

Álvarez-Pinazo, G., Cuesta, A., Garcia-Maté, M., Santacruz, I., Losilla, E.R., La Torre, A.G.D., León-Reina, L. and Aranda, M.A.G. (2012). A practical guide to microstructural analysis of cementitious materials. Boca Raton, FL: CRC Press.

Andersen, M.D., Jakobsen, H.J. and Skibsted, J. (2004). Characterization of white Portland cement hydration and the C-S-H structure in the presence of sodium aluminate by ${ }^{27} \mathrm{Al}$ and ${ }^{29} \mathrm{Si}$ MAS NMR spectroscopy Cement and Concrete Research, 34(5), 857-868. doi: 10.1016/j.cemconres.2003.10.009

EN/TC 51/WG 6 (2011). EN 197-1: Cement - Part 1: Composition, specifications and conformity criteria for common cements.

Grimmer, A.R., von Lampe, F. and Mägi, M. (1986). Solid-state high-resolution ${ }^{29}$ Si MAS NMR of silicates with sixfold coordinated silicon Chemical Physics Letters, 132(6), 549-553. doi: 10.1016/0009-2614(86)87122-6

Irassar, E.F. (2009). Sulfate attack on cementitious materials containing limestone filler - A review Cement and Concrete Research, 39(3), 241-254. doi: 10.1016/j.cemconres.2008.11.007

Kunther, W., Lothenbach, B. and Skibsted, J. (2015). Influence of Ca/Si ratio of the C-S-H phase on the interaction with sulfate ions and its impact on the ettringite crystallization pressure Cement and Concrete Research, 69, 
Konstantinos Sotiriadis, Michal Hlobil, Jaromír Toušek, Dita Machová, Petra Mácová, Michal Vopálenský and Alberto Viani

37-49. doi: 10.1016/j.cemconres.2014.12.002

L' Hôpital, E., Lothenbach, B., Le Saout, G. and Kulik, D. (2015). Incorporation of aluminium in calcium-silicatehydrates Cement and Concrete Research, 75, 91-103. doi: doi:10.1016/j.cemconres.2015.04.007

Ma, X., Çopuroğlu, O., Schlangen, E., Han, N. and Xing, F. (2018). Expansion and degradation of cement paste in sodium sulfate solutions Construction and Building Materials, 158, 410-422. doi: 10.1016/j.conbuildmat.2017.10.026

Rawal, A., Smith, B.J., Athens, G.L., Edwards, C.L., Roberts, L., Gupta, V. and Chmelka, B.F. (2010). Molecular silicate and aluminate species in anhydrous and hydrated cements Journal of the American Chemical Society, 132(21), 7321-7337. doi: 10.1021/ja908146m

Richardson, I.G., Brough, A.R., Brydson, R., Groves, G.W. and Dobsont, C.M. (1993). Location of aluminum in substituted calcium silicate hydrate (C-S-H) gels as determined by ${ }^{29} \mathrm{Si}$ and ${ }^{27} \mathrm{Al}$ NMR and EELS Journal of the American Ceramic Society, 76(9), 2285-2288. doi: 10.1111/j.1151-2916.1993.tb07765.x

Richardson, I.G., Skibsted, J., Black, L. and Kirkpatrick, R.J. (2010). Characterization of cement hydrate phases by TEM, NMR and Raman spectroscopy Advances in Cement Research, 22(4), 233-248. doi: 10.1680/adcr.2010.22.4.233

Tsivilis, S., Batis, G., Chaniotakis, E., Grigoriadis, G. and Theodossis, D. (2000). Properties and behavior of limestone cement concrete and mortar Cement and Concrete Research, 30(10), 1679-1683. doi: $10.1016 /$ S0008-8846(00)00372-0

Walkley, B, and Provis, J.L. (2009). Solid-state nuclear magnetic resonance spectroscopy pf cements Materials Today Advances, 1, 100007. doi: 10.1016/j.mtadv.2019.100007

Worrell, E., Kermeli, K. and Galitsky, C. (2013). Energy efficiency improvement and cost saving opportunities for cement making: An ENERGY STAR ® guide for energy and plant managers. Berkeley, CA: Lawrence Berkeley National Laboratory.

Yang, Y., Zhang, Y., She, W., Liu, N. and Liu, Zh. (2018). In situ observing the erosion process of cement pastes exposed to different sulfate solutions with X-ray computed tomography Construction and Building Materials.


Register for free at https//www.scipedia.com to download the version without the watermark 